\title{
Technology Adoption Among Higher Education Institutions in Malaysia: An Analysis of Business Intelligence Adoption
}

\author{
Yulita Hanum P Iskandar (Corresponding author) \\ Graduate School of Business, Universiti Sains Malaysia, 11800 USM, Malaysia \\ E-mail: yulita@usm.my
}

\begin{abstract}
Shahrizal Nazri
Centre of Knowledge, Communications \& Technology, Universiti Sains Malaysia, 11800

USM, Malaysia

E-mail: shahrizal@usm.my
\end{abstract}

Received: March 17, $2021 \quad$ Accepted: April 22, $2021 \quad$ Published: May 15, 2021

doi:10.5296/ijssr.v9i2.18422 URL: https://doi.org/10.5296/ijssr.v9i2.18422

\begin{abstract}
Purpose: The study strives to determine the outcomes of business intelligence (BI) adoption among Malaysian Higher Education Institutions and factors that affect its adoption.

Research methodology: The research design is formulated in the context of a quantitative research strategy for this study. The study used the e-mail survey questionnaire as a method for collecting data. 769 public and private HEIs listed by the Malaysia Qualification Agency participated in the analysis. Structural Equation Mode (SEM) is utilized to collect data.

Findings: Overall findings show that HEIs in Malaysia are at the moderate level of BI adoption. Technology: Complexity Environment: Competitive Pressure describes the significant factors of BI adoption among HEIs in Malaysia.

Practical implications: The researcher also hopes that the model of this study can be used for analysing other IT adoptions in the context of the HEIs. Also, the researcher expects that the empirical finding in this research from the validated template will provide further knowledge of the benefits of HEIs adoption of BI in Malaysia.

Originality/Value: There is insufficient research in the area of BI adoption in HEIs. The
\end{abstract}




\section{Macrothink}

International Journal of Social Science Research

ISSN 2327-5510

2021, Vol. 9, No. 2

objective of this analysis is therefore to assess the factors and results of BI adoption by Malaysian HEIs. The researcher also expects that the model for this study may be used in the review of other IT adoptions in the HEI sense.

Keywords: business intelligence, adoption, and higher education institutions 


\section{Introduction}

The foundation of the power of the organization has shifted from property, finance and material to intangible assets (Olszak, 2016). With the advancement of information technology, increased competition, fabulous product or service flexibility, and increased customer and stakeholder demands, organizations need to operate in a highly complex and dynamic environment. Organizations that maintain this vibrant atmosphere need to choose a timely, effective and efficient manner. However, many organizations are faced with the challenge of overloading data. As stated from International Data Corporation (IDC), the world's digital data will grow from 33 zettabytes to 175 zettabytes by 2019, an increase of $61 \%$ by 2025, with 90 per cent of the information being unstructured and residing in the cloud as in data centres.

BI has emerged as an effective administrative and academic tool in the higher education system (HE) (DELL, 2013). BI can be employed by HEI administrators to assist in activities that generate massive amounts of data that can later be transformed into insights. Among these include tracking semester enrolment figures, managing the HEIs financial year budgeting and measuring success of fundraising activities (JISC, 2016). Faculties and departments can use BI tools to better improve their course offerings by tracking and measuring student performance to ensure curriculum effectiveness and more targeted assistance for failing students who need help (JISC, 2016). Nevertheless, even as BI is commonly reflected in business for-profit organizations, the HEIs are another potential impact area for BI applications. According to Dressner (2018), the insurance industry leads all others into the penetration of BI adoption, followed by the technology industry, whereas HE has shown the low penetration of BI adoption.

\subsection{The Relevance of BI to HEIs in Malaysia}

The progression of HEIs has developed globally in Malaysia, with the impact of institutional positions in financial, human capital and marketing decision-making (Locke, 2011). A trend towards a more holistic definition of the internationalization of higher education has been created through the rapid deployment of IT in massive open online courses (Rui Yang, 2001; Altbach, 2007; Knight, 2007; Mok, 2007; Healey, 2008; Hudjik, 2011).

The changes in HEIs have also global impacts in Malaysia. It is also well observed. When HE systems are grown, the quality of education is more regulated. The Malaysia Qualification Agency (MQA) was formed to provide increased responsibility, particularly for the quality and performance of HEIs as a national quality assurance and accreditation bodies. Malaysia's diverse higher education landscape has seen the widespread emergence of both public and private institutions. These institutions include universities, polytechnics, college universities and community colleges. According to MQA, there are currently 769 institutions that match the categorization (see Table 1). 
Table 1. Number of registered public and private higher education institutions in Malaysia. Malaysia Qualification Agency (MQA), http://www2.mqa.gov.my

\begin{tabular}{lcll}
\hline Public HEIs & \multicolumn{3}{l}{ Private HEIs } \\
\hline Public Universities & 37 & Private Universities & 80 \\
Polytechnics & 33 & Private University Colleges & 40 \\
Community Colleges & 181 & Private Colleges & 398 \\
TOTAL & 251 & TOTAL & 518 \\
Total of public and private higher education institutions in Malaysia $=769$ & \\
\hline
\end{tabular}

The BI study in Malaysia's HEIs is relevant for several reasons. Firstly, the HE sector has undergone a number of reforms aimed at improving the standard of education and attracting foreign students (Malaysia Ministry of Education (MoE, 2015). Such reforms led to the entry of foreign students into the HEIs of Malaysia.

Available statistics (Figure 2), as shown in 2015, indicate that there are a total of 74,748 foreign students enrolled in HEIs in Malaysia from more than 150 countries. 48,343 of these are private HEIs, while the remaining 26,405 are public HEIs. Despite the increase in enrolment of foreign students from different countries in Malaysia's HEIs, BI adoption remains critical to the better use of student data and HEI operations.

Second, BI adoption is becoming increasingly popular with Malaysian organizations in the Asia Pacific region. For example, according to Gartner, Malaysia would continue to be the second-largest business intelligence market in ASEAN after Singapore, reaching USD 30.4 million by 2017, while demand for Asia Pacific BI is projected to increase revenue by 7.4 per cent to approximately USD 1.4 billion in 2014 and more than USD 1.6 billion in 2017 . Within the context of Malaysia, therefore, the prospect of BI is undoubtedly bright and, therefore, the importance of BI adoption research in the setting of HEI.

HEIs are an essential institution for the production of the workforce in all countries (Ong, 2016). Typically, these institutions are complicated and involve massive data sources across departmental boundaries to achieve academic excellence (Rahmat, Ahmad, \& Ta'a, 2016; Wong, 2017; Wong et al., 2018). In general, the HEIs comprises five business areas: (1) student affairs; (2) academic staff affairs; (3) finance affairs; (4) research and development affairs; and (5) development of infrastructure (Rahmat et al., 2016). Each business area uses different system for their respective needs and this needs to be integrated. This is because data generated from each application contain useful information that should be accessible by multiple departments such as HEI senior management, faculty, university administrators, scientists and relevant decision makers (Rahmat et al., 2016; Wong, 2017; Wong et al., 2018).

The BI industry has created tools that can be used to support improving an HEI's academic goals. Data are becoming an increasingly important need for organizations of all sizes. The high level of Internet use, consumption of online commerce, and social media have generated large data that can be used to better evaluate the market, its customers, competitors, and finances (EDUCASE, 2017). Therefore, HEI administrators understand the high-value BI that 
they can offer to promote their academic goals (EDUCASE, 2017). BI has become, patently, essential for improving the decision-making process in today's organizations; after that, for achieving competitive advantages in the industry. The adoption of BI in HEIs must therefore, be significantly disclosed through a sound research study. However, in general terms, the current researchers have only emphasized the phases of adoption. By having information on the stages of BI adoption, awareness among the HEIs will be established.

\subsection{Limitations in BI Adoption}

Literature on BI adoption has largely focused on its applications in the business sector, (Boonsiritomachai et al., 2016; Qushem, 2017; Ramamurthy, Sen, \& Sinha, 2008; Shen, Hsu, \& Peng, 2012) while studies for the HEI sector have been scarce. Although the trend in decision-making support tools continues to increase, HEIs have been lagged behind in the adoption of BI (Rahmat et al., 2016). In most cases, some HEIs still use spreadsheets to analyse data. While these spreadsheets are convenient to use, simple to configure and effective in delivering quick results, spreadsheets are designed for individual efficiency rather than for organizational applications (Jain \& Kanungo, 2013), therefore, data entry errors could occur regularly, resulting in frequent significant cumulative errors (Bishop \& McDaid, 2008). The poor quality of the data collection could have an impact on the negative consequences and future decision-making of the organization (Haug, Zachariassen, \& van Liempd, 2011).

A review of existing research shows that the majority of BI adoption studies have been conducted in developed countries (Boonsiritomachai et al., 2016; Elbashir et al., 2008; Owusu, 2017; Owusu \& Moyaid, 2016; Ramamurthy et al., 2008; Trieu, 2017). Although IT spending in this region is growing significantly, the available literature has barely found BI adoption in developing countries. The BI adoption trend was clarified by a herding process through which social actors converge and behave inconsistently (Bikhchandani, Hirshleifer, \& Welch, 1998; Duan, Gu, \& Whinston, 2009; Shim et al., 2018). The behavior of herds in BI adoption is prevalent and there has been an increasing focus of research (Duan et al., 2009; Shim et al. 2018). BI Adoption Literature promotes the implementation of individual stages of software applications and services. (Brynjolfsson \& Kemerer, 1996; Duan et al., 2009) while BI organizational-level research is rare, with the exception of a few studies (Boonsiritomachai et al., 2016; Chavesuk \& Horkondee, 2015; Hatta et al., 2017; Puklavec et al., 2014; Sujitparapitaya et al., 2012).

Since there is insufficient research on HEI adoption in developing countries, knowledge of the behavior of HEIs in the adoption of BI is inadequate for prediction and clarification. This research is based on a lack of understanding of the antecedent of HEI-related BI adoption in developing countries. The main issue is that the adoption of BIs between HEIs in a developing country does not address any research context.

This study will analyse the factors and outcomes of the adoption of BI among Malaysian HEIs based on the issues stated above. In addition, this study will examine the consequence of BI adoption in affecting organizational performance. 


\section{Method}

\subsection{Design}

For this study, a quantitative analysis approach is used in the research process. The study used an email survey questionnaire as a method for collecting data. Firstly, invitation emails were sent to HEIs registered and recognized by the Malaysia Ministry of Higher Education (MoHE). The main target group were individuals with intimate knowledge of their organizations IT planning and infrastructure. These individuals ranged from C-suite personnel such as the Chief Information Officer (CIO) to lower-ranked personnel such as IT Managers or IT Executives. The survey questionnaire was made using Google Forms with the links attached in the emails sent to the survey participants. The list of potential survey participants was obtained from MoHE. A cover letter describing the purpose and intent of the survey was provided on the first page of the Google Forms questionnaire, which confirmed that the responses were entirely anonymous.

\subsection{Sample}

A total of 769 public and private HEIs listed in the Malaysia Qualification Register (MQR) by the Malaysia Qualification Agency (MQA) were sampled in this current study. The list of HEI organizations has been obtained from MoHE. These institutions comprised of public and private universities, colleges, polytechnics, and community colleges.

\subsection{Measurement Items}

Items in the questionnaire related to the constructs of the study, which were adopted and adapted from previous studies. The 5-point Likert scale used in this study is arranged from 1 (strongly disagree) to 5 (strongly agree), which is often used in prior research.

The questionnaire consisted of four different sections. Section I consisted of demographic information questions. Section II contained questions on BI adoption. The constructs and measures for classifying these levels of BI adoption information use in organizations adapted from the IEM checklist (Davis, Miller, \& Russell, 2006).

Section III comprised questions on the antecedents of BI adoption. Relative advantage, complexity, compatibility, trialability, and observability were adapted from Moore and Benbasat (1991). Four items for absorptive capacity adapted from Ramamurthy et al. (2008). Resource availability adapted from Iacovou et al. (1995), and competitive pressure adapted from Grandon and Pearson (2004). The final section included questions for constructing the BI adoption outcome in terms of organizational performance, which was adapted from Owusu (2016).

\subsection{Data Collection}

The first batch of survey results was collected within two weeks. 62 questionnaires were completed. HEIs which did not respond were sent a reminder email. The second batch of questionnaires was collected after two more weeks, with another 80 responses obtained. This came up to a total of 142 responses representing a response rate of $18.46 \%$. 


\section{Macrothink \\ International Journal of Social Science Research \\ ISSN 2327-5510 \\ 2021, Vol. 9, No. 2}

Considering the minimum sample size of 139 targets, the low response rate usually reported in social science studies was deemed to be acceptable (Sekaran \& Bougie, 2016). The assumption was made for this initial sample size of 55 cases with a power requirement of 0.8 and an alpha (significance) level of 0.05 and medium effect size, as stated by Cohen and Levinthal (1990). Therefore, the initial sample size was 90 cases to reach adequate power testing of the structure of a research model. The responsiveness of this study is however similar to those in other Malaysian organizational studies. Such as Behyan et al.'s work in 2015, 19.48 percent observed with 120 behavioral samples, 10.07 percent with 106 samples reported Mad Lazim and Ramayah (2010) and 10.60 percent with 228 Siew-Phaik et al. reported (2013)

The collected data have been recorded and analyzed utilizing the structural equation model (SEM). SEM is a worthwhile method for multivariate applied theory testing and casual modelling (Reisinger \& Mavondo, 2006). The technique for evaluating and defining a multivariate analysis framework (Hair et al., 2017) has become a powerful approach for multivariate applied testing and causal modelling (Reisinger \& Mavondo, 2006). SEM is able to integrate several regression and factor analysis dimensions in many associated dependence interactions between latent and measurable variables as well as between latent variables. (Hair et al., 2017).

\section{Results}

\subsection{Demographic Profile of Responding HEIs}

Table 2 shows the demographic profile of the participating HEIs. The majority of the HEIs are from Private Colleges (27.8 per cent), followed by Private University (24.7 per cent). Regarding geographical location, most HEIs are in Selangor (25.9 per cent) and Kuala Lumpur (13.0 per cent). 


\section{Macrothink}

Table 2. Number of registered public and private higher education institutions in Malaysia. Malaysia Qualification Agency (MQA), http://www2.mqa.gov.my

\begin{tabular}{lll}
\cline { 1 - 2 } Demographic Variable & Frequency & Percentage (\%) \\
\cline { 1 - 2 } Category of HEI & 21 & 13.0 \\
Public University & 23 & 14.2 \\
Polytechnic & 14 & 8.6 \\
Public College & 40 & 24.7 \\
Private University & 19 & 11.7 \\
Private College & 45 & 27.8 \\
Private College & & \\
State of HEI & 11 & 6.8 \\
Johor & 7 & 4.3 \\
Kedah & 4 & 2.5 \\
Kelantan & 5 & 3.1 \\
Melaka & 12 & 7.4 \\
Negeri Sembilan & 12 & 7.4 \\
Pahang & 10 & 6.2 \\
Perak & 5 & 3.1 \\
Perlis & 10 & 6.2 \\
Pulau Pinang & 6 & 3.7 \\
Sabah & 6 & 3.7 \\
Sarawak & 42 & 25.9 \\
Selangor & 11 & 6.8 \\
Terengganu & 21 & 13.0 \\
Kuala Lumpur & &
\end{tabular}

\subsection{Measurement Model Results}

The model was tested by analysis of individual load, internal composite reliability (CR) and discriminatory validity to ensure the quality and reliability of the findings. In the context of the Reflective Measurement Model, two forms of validity, which are mutually valid and discriminatory. Secondly, the reflective estimation paradigm has been tested for convergent validity. The indicator expenses, CR and average variance (AVE) were evaluated (Hair et al., 2014, 2017; Ramayah et al., 2018).

Reliability refers to consistency or repeatability over time (Hair et al., 2017). Generally, Cronbach's alpha is the most widely used criterion for internal consistency reliability. However, Hair et al. (2014) argued that Cronbach's alpha might underestimate the internal consistency reliability due to its sensitiveness to the number of items on a scale. Hence, they have suggested using composite reliability (CR) to test reliability more appropriately. CR values should be more than 0.70 , a value from 0.60 to 0.70 is acceptable in exploratory research (Hair et al., 2017), and values less than 0.60 are unreliable (Hair et al., 2014). Similarly, indicator reliability was evaluated, wherein each indicator loading should be 
0.50 or higher (Hair et al., 2014). Table 3 shows the results.

Table 3. Measurement model

\begin{tabular}{llll}
\hline Constructs & Loading & $\begin{array}{l}\text { Average Variance } \\
\text { Extracted (AVE)a }\end{array}$ & $\begin{array}{l}\text { Composite Reliability } \\
\text { (CR)b }\end{array}$ \\
\hline BI Adoption & 0.784 & 0.609 & 0.857 \\
Technology: Relative Advantage & 0.882 & 0.607 & 0.858 \\
Technology: Complexity & 0.669 & 0.692 & 0.899 \\
Technology: Compatibility & 0.972 & 0.801 & 0.922 \\
Technology: Trialability & 0.971 & 0.869 & 0.964 \\
Technology: Observability & 0.750 & 0.722 & 0.911 \\
Organization: Absorptive Capacity & 0.691 & 0.616 & 0.826 \\
Organization: Resource Allocation & 0.969 & 0.670 & 0.795 \\
Environment: Competitive Pressure & 0.836 & 0.846 & 0.956 \\
Organizational Performance & 0.824 & 0.646 & 0.959 \\
\hline
\end{tabular}

\subsection{Structural Model Assessment}

The assessment of the conceptual design was reported by the efficiency and accuracy of the development phases. It analyzes the analytical ability and relationships of the tested model between the systems. Research on the structural model provides findings from normal assessments of the model, regular bootstrapping and blindfolding by Hair et al. (2017).

This study finds 10 similar correlations between the two structures. Smart PLS 3.0 Bootstrapping has been established to validate the significance of any hypothesis. In keeping with the manner in which the coefficient was calculated as seen in Table 4, four t-value ratios were $>2.33$; eventually quantitative at the significance level; and substantive at the significance level of 0.05 . Six relationships have also been considered to be negligible. 
Table 4. Hypothesis testing

\begin{tabular}{|c|c|c|c|c|c|c|}
\hline Relationship & $\begin{array}{l}\text { Path } \\
\text { coefficient }\end{array}$ & $\begin{array}{l}\text { Std } \\
\text { Error }\end{array}$ & T-value & p-value & $\mathbf{R}^{2}$ & Decision \\
\hline Technology: Relative Advantage-> BI Adoption & 0.215 & 0.222 & 0.966 & 0.167 & & Not supported \\
\hline Technology: Complexity -> BI Adoption & -0.514 & 0.125 & 4.099 & 0.000 & & Supported $* *$ \\
\hline Technology: Compatibility -> BI Adoption & 0.266 & 0.191 & 1.390 & 0.083 & & Not supported \\
\hline Technology: Trialability -> BI Adoption & -0.563 & 0.118 & 4.759 & 0.000 & 0.627 & Supported $* *$ \\
\hline Technology: Observability -> BI Adoption & 0.245 & 0.161 & 1.526 & 0.064 & & Not supported \\
\hline Organization: Absorptive Capacity -> BI Adoption & -0.294 & 0.165 & 1.782 & 0.038 & & Not supported \\
\hline Organization: Resource Allocation -> BI Adoption & 0.123 & 0.098 & 1.257 & 0.105 & & Not supported \\
\hline Environment: Competitive Pressure -> BI Adoption & 0.349 & 0.177 & 1.974 & 0.024 & & Supported $* *$ \\
\hline BI Adoption $->$ Organizational Performance & -0.308 & 0.073 & 4.205 & 0.000 & 0.095 & Supported** \\
\hline
\end{tabular}

Note. *T-value $>1.96, * *$ P-value $<0.05$.

The findings also disclosed that relative advantage; complexity, compatibility, trialability, observability, absorptive capacity, resource availability, and competitive pressure factor were able to explain the 62.7 per cent of the variance in BI Adoption. Meanwhile, BI Adoption explained 9.5 per cent of the variance in organizational performance. As shown in Cohen (1988), the R2 values of 0.627 and 0.26 surpassed the scale of the broad sample. In addition, as suggested by Falk and Miller (1992), the R2 values of 0.109 were above 0.10, recommending that the $\mathrm{R} 2$ value be equal to or above 0.10 for the variance of the endogenic structure to be considered adequate. As a result, R2 for the construction of the research model was similar to recent literature findings (Hair et al., 2017).

\subsection{Importance-Performance Matrix Analysis (IPMA)}

The Importance-Performance Matrix Analysis (IPMA) extends the standard PLS-SEM outcomes of path coefficient evaluations by the accumulation of a dimension to examine the average values of the latent variables (Hair). IPMA allows researchers to understand more and to report the findings of management involvement. IPMA may provide a valuable and simple guide to classifying the most significant features of products or services in relation to their management needs (Hair et al., 2017). According to Ringle and Sarstedt (2016), IPMA intended to identify predecessors with a robust overall effect and comparatively low performance (low average latent variable score) that are relatively important for objective development. The main precedent for enhancing BI adoption among HEIs in Malaysia was found in the IPMA research reported.

The focus of the IPMA is on one key target construct of interest-based on the PLS path model. In this research, BI adoption represents a key target construct. Therefore, the importance-performance values of BI adoption's form construct (relative advantage, complexity, compatibility, trialability, observability, absorptive capacity, resource availability, competitive pressure, and vendor selection) allowed the creation of the importance-performance map of BI Adoption. Table 5 below is the summary of the value for 
the map.

Table 5. Summary value

\begin{tabular}{lll}
\hline Construct & $\begin{array}{l}\text { Importance (total effects) } \\
\text { for BI Adoption }\end{array}$ & $\begin{array}{l}\text { Performance (BIA) } \\
\text { (Index Values) }\end{array}$ \\
\hline Technology: Relative Advantage & 0.305 & 83.946 \\
Technology: Complexity & -0.550 & 65.194 \\
Technology: Compatibility & 0.253 & 76.849 \\
Technology: Trialability & -0.653 & 75.515 \\
Technology: Observability & 0.241 & 65.465 \\
Organization: Absorptive Capacity & -0.392 & 70.264 \\
Organization: Resource Allocation & 0.168 & 75.426 \\
\hline
\end{tabular}

Furthermore, the result of Table 5 becomes a substance to create an importance-performance of BI Adoption's map. The map is presented with two axes, which are the x-axis and the $\mathrm{y}$-axis. Since the target is BI Adoption, the $\mathrm{x}$-axis represents the importance of relative advantage, complexity, compatibility, trialability, observability, absorptive capacity, resource availability, competitive pressure, and vendor selection explaining the target construct of BI adoption. At the same time, the y-axis illustrates the performance of the same construct with the $\mathrm{x}$-axis. The importance or $\mathrm{x}$-axis is named total effects, while the performance or $\mathrm{y}$-axis is BIA.

Based on the importance-performance map above (see Figure 3: IPMA Diagram), relative advantage has the highest performance (83.946) and the highest important (0.305) variable in the prediction of BI adoption. The next two constructs that are more important are competitive pressure (0.296), and compatibility (0.253). The compatibility is slightly lower. Thus, the HEIs administrator should focus on issues of competitive pressure to improve BI adoption. In terms of competitive pressure, the performance has little in the context of BI adoption, because it is low on performance and even slightly high in importance. Based on the IPMA result, it is shown that a one-unit increase in competitive pressure performance would increase the performance of BI adoption by 0.296 points. 


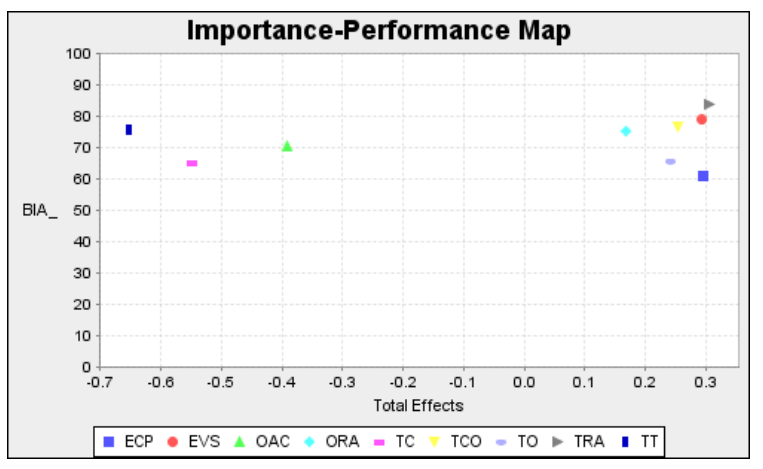

Figure 1. Figure 3. IPMA Diagram

Note $. \mathrm{BIA}=\mathrm{BI}$ Adoption, $\mathrm{TRA}=$ Relative Advantage, $\mathrm{TC}=$ Complexity, $\mathrm{TCO}=$ Compatibility, $\mathrm{TT}=$ Trialability $\mathrm{TO}=$ Observability, $\mathrm{OAC}=$ Absorptive Capacity, $\mathrm{ORA}=$ Resource Availability, $\mathrm{ECP}=$ Competitive Pressure 。

\section{Discussion}

\subsection{Business Intelligence Adoption Among HEIs in Malaysia}

Data analysis revealed that none of the participating HEIs were BI adoption at the highest level, which was a category of innovation. Only $6.17 \%$ of the participating HEIs are at the lowest level of BI adoption, which was the operating category. Then followed the optimization category (19.14 per cent), which was the fourth level of BI adoption. Most of the participating HEIs fall within the integration category (37.65 per cent), which was the second level of BI adoption, and the consolidation category (37.04 per cent), which was the third level of BI adoption. Due to the high number of HEIs categorized as second and third levels of BI adoption, HEIs in Malaysia are at a moderate level of BI adoption. The category of operation is the starting point for BI adoption and, at this level, does not require a comprehensive IT infrastructure to be implemented and is not complicated. In order for HEIs to be transformed into a category of consolidation and integration, an emphasis must be placed on analytical processes, the development of their human capital, knowledge processes, culture and IT infrastructure that provide information distribution. However, only a minority has been categorized as having higher levels of BI adoption, which is a category of optimization because HEIs in Malaysia do not have those resources. With these results, there is ample room for increasing Malaysian HEIs to the highest level of BI adoption and the antecedents of HEI adoption in Malaysia need to be considered.

The nine antecedents of adoption of the BI were verified in this study. The consequences of each antecedent will be discussed in the section below.

\subsection{Relationship Between Relative Advantage and Business Intelligence Adoption}

The relative advantage of $\mathrm{BI}$ is not a significant antecedent of $\mathrm{BI}$ adoption. This result runs counter to most prior studies and Rogers' theory of DOI. From the IT adoption perspective, this result is a departure from previous studies that was relative advantage found as a significant antecedent of IT adoption such as ICT adoption (Alam \& Noor, 2009), e-business 
adoption (Jeon, Han, \& Lee, 2006), e-commerce (Ghobakhloo \& Tang, 2013; Grandon \& Pearson, 2004), electronic customer relationship management (Sophonthummapharn, 2009), accounting information system (Ali et al., 2012) and enterprise resource planning (Chang, Hung, Yen, \& Lee, 2010).

This finding has many possible explanations. Firstly, the inconsistent findings could be due either to the study context or to the sector used in the studies. Previous appropriate studies focusing on BI adoption were taken from SMEs (Boonsiritomachai et al., 2016; Chaveesuk \& Horkondee, 2015; Grandon \& Pearson, 2004; Hatta et al., 2017), but less attention has been given to HEIs. In terms of focus on BI adoption, the nature of these sectors could differ from HEIs in Malaysia. SMEs tend to emphasize BI adoption to reap economic advantages (Olszak, 2016; Popovič et al., 2018), while HEIs may not necessarily view BI adoption the same way.

\subsection{Relationship Between Complexity and Business Intelligence Adoption}

The results of this research indicate that BI's complexity serves an essential part in the antecedent of BI adoption among HEIs, which supports Rogers' DOI theory. Several previous studies also support the suggested hypothesis of this research, which noted the adverse effect of the complexity of IT innovation on the organizational IT adoption (Chang et al., 2010; Jeon et al., 2006; Sophonthummapharn, 2009).

According to Rogers (2003), the complexity of technology depends on how difficult it is to understand and use technology. Past surveys have shown that high-complexity IT innovation requires improved technical skills and more excellent performance and organizational commitment to enhance its likelihood of adoption (Alam \& Noor, 2009; Bradford \& Florin, 2003). Since BI was the more complicated IT innovation than most other IT developments, this complexity could pose considerable challenges for HEIs to adopt BI. Generally, HEIs need to improve its technology capability and BI skills in their organizations (Puklavec et al., 2018; Sahay \& Ranjan, 2008). In this research, the value of BI is demonstrated by BI's institutional understanding of the complexity of adoption, learning difficulties and resistance to BI adoption.

\subsection{Relationship Between Compatibility and Business Intelligence Adoption}

The compatibility of $\mathrm{BI}$ is not a significant antecedent of BI adoption. This result runs counter to most prior studies and Rogers' theory of DOI. Much earlier research found IT adoption significantly affected by IT innovation compliance and past organizational experience, existing value, operating methods, and IT facilities (Ghobakhloo et al., 2011; Grandon \& Pearson, 2004; Lal, 2007). For example, a study by Ghobakhloo et al. (2011) on the e-commerce adoption among manufacturing SMEs discovered that the internet systems adoption by SMEs before perceiving e-commerce applications was consistent with their organization and became one of the most significant precedents of e-commerce adoption.

The findings of this study are not unprecedented as previous studies by Ifinedo (2011) on the adoption of e-business among SMEs in Canada have found insignificance in the relationship between compatibility and BI adoption. Comparably, Ali et al. (2012) found that compatibility is not significantly related to the adoption of accounting information systems by 
SMEs in Malaysia. While compatibility in organizations has been discovered to have no significance on the adoption of IT, this does not merely imply that BI is not consistent with the businesses of the HEIs. The results show that the overall perceived compatibility was relatively high for four levels of BI adoption categories far higher than neutral assessment (see Table 4). This may mean that all forms of BI feel aligned not only with their current working practices but also with HEI principles and beliefs. The high average values may probably be explained by the BI's being not the only IT innovation the organization runs but also to help analyze user access and information sharing that is required (Sahay \& Ranjan, 2008). Therefore, HEIs may not need to dramatically shift their standard business practices even with the adoption of BI. This reason could explain why HEI administrators view BI as aligned with current business practices.

\subsection{Relationship Between Trialability and Business Intelligence Adoption}

The trialability of BI was found as a significant factor of BI adoption. That result is consistent with the Rogers' theory of DOI and both the suggested hypothesis and several prior study results that trialability has a significant effect on IT adoption (Chen, 2004; Kendall, Tung, Chua, Ng, \& Tan, 2001; Ramdani et al., 2013). The adoption of new IT innovation often leads to the confusion that usually impacts the level of adoption. To minimize ambiguity, an organization that presents such development in IT should allow potential users to attempt it before constructing an investment decision (Kendall et al., 2001; Ramdani et al., 2013). Ramdani et al. (2013) stated that organizations and individuals that have attempted and tested IT innovations usually embrace faster than those that have not.

\subsection{Relationship Between Absorptive Capacity and Business Intelligence Adoption}

The results of this study specify that organizational absorptive capacity serves an essential part in the antecedent of BI adoption (Cohen \& Levinthal, 1990; Khalifa \& Davison, 2006; Lal, 2007; Lertwongsatien \& Wongpinunwatana, 2003). This result is similar to the technology-organization-environment (TOE) theory and other studies that show how organizational absorptive capacity can drive their organizations for IT adoption (Cohen \& Levinthal, 1990; Khalifa \& Davison, 2006; Lal, 2007; Lertwongsatien \& Wongpinunwatana, 2003).

\subsection{Relationship Between Resource Availability and Business Intelligence Adoption}

This finding disagrees with the technological-organizational-environmental (TOE) theory as well as the results of the majority of previous research that organizational resource availability was significantly related to IT adoption (Ali et al., 2012; Grandon \& Pearson, 2004; Iacovou et al., 1995; Khalifa \& Davison, 2006).

HEIs have to be prudent with their capital expenditure and investments and thus most HEIs inadequately invest in their IT infrastructure. (Wong, 2017; Wong et al., 2018). The observant is because a suboptimal IT investment decision could have severe adverse financial implications contributing to debt and economic collapse (Ghobakhloo et al., 2011). Also, the $\mathrm{BI}$ and its elements involve long-term expenditure incorporating high-cost IT facilities (Popovič et al., 2018). Also, HEIs are usually unable to satisfy other related and extra IT 
adoption costs, such as employing IT professionals, providing staff training, and organizational restructuring (Dawson, Heathcote, \& Poole, 2010; Wong, 2017). Therefore, only HEIs with sufficient economic assets consider BI adoption as a viable venture to pursue (Wong, 2017; Wong et al., 2018).

However, other researchers have discovered that some variables related to the availability of organizational resources are not significantly affected by IT adoption (Buonanno et al., 2005; Duan et al. 2012; Sarosa \& Underwood, 2005). For example, Sarosa and Underwood (2005) noted that the drastically decreasing hardware and software prices in recent years have made IT expenditure not a vital consideration that hinders the adoption of IT in HEIs, even though it has inadequate financial resources. Duan et al. (2012) also argued that monetary factors have not been identified as issues that prevent organizations from adopting internet systems, as the majority of IT adoptions can be achieved in-house without the acquisition of significant expenditure. The probable understanding of the contradictory findings implemented by HEI may clarify the various forms of IT invention. For instance, Duan et al. (2012) concluded that there were no major effects on e-commerce availability on organizational capital. However, this research typically entails BI more challenging and expensive implementation that needs more financial and technological commitment than low-end innovations (Hwang et al., 2004).

Thus, it is conceivable that some Malaysian HEIs consider BI to be inexpensive and only suitable for large enterprises. BI was viewed as a risky investment and unsuitable for the context of HEIs (Sujitparapitaya et al., 2012). Consequently, the results do not support the availability of resources as an antecedent of BI adoption among HEIs.

\subsection{Relationship Between Competitive Pressure and Business Intelligence Adoption}

Competitive factors were established as a major background of IT adoption, in line with prior studies (Alshawi et al., 2011; Duan et al., 2012; Ghobakhloo et al., 2011). The findings of this research show that competitive pressure in the Malaysian context has a vital role in the adoption of BI among HEIs. Malaysian HEIs who are engaged in a more competitive setting are more likely to adopt BI. These findings coincide with previous findings and the technological-organizational-environmental (TOE) theory that market competition is the driving force behind IT adoption (Alshawi et al., 2011; Dholakia \& Kshetri, 2004; Duan et al., 2012; Ghobakhloo et al., 2011).

Recently, with rapid IT development, HEIs face more difficulties than changing the organizational behavior of many organizations. These economic stresses mean that other HEIs have begun to embrace IT development to enhance their organizational efficiency (Puklavec et al., 2018). HEIs cannot retain competitiveness based on their intuition (Hocevar \& Jaklič, 2010; Puklavec et al., 2018). The decision-making method in HEIs has shifted due to new data requirements, and decision-making needs to focus on accurate data (Wong, 2017). Since the choices of HEI administrators are generally focused on intuition, and the policies developed are focused on the limited vital capacity of managers, HEIs often struggle to meet and achieve their corporate objectives, resulting in their lack of competitiveness (Wong, 2017; Wong et al., 2018). Consequently, HEIs could strive to compete if they do not adopt decision 
support systems (Ong, 2016).

\subsection{Relationship Between Business Intelligence Adoption and Organizational Performance}

Empirical results revealed that BI adoption had a significant impact on the success of Malaysia's organization. This implies that the BI adoption in HEIs enables employees to build customer value, manage their service delivery capabilities and strengthen operational efficiency (Kaplan \& Norton, 1996). As Kaplan and Norton (1996) have indicated, HEIs will outline major procedures and competencies, including processing times, efficiency, skills and productivity, and identify ways to ensure them through continuous improvement of the quality attributed to BI adoption. These refer to the HEI stratification for the different objectives of the business process (Kaplan \& Norton, 2004).

\section{Implications}

The results of the study contributed to a number of implications; firstly, broadening awareness of the organization's analytical resources to support and close the knowledge gap in BI adoption by providing better understanding to HEI administrators that helps build optimistic perceptions of BI adoption. HEI managers should also be motivated to become more involved in the adoption of BI by improving efficiency and competitiveness in order to improve their chances of success in decision-making.

Second, the potential outcomes of this study will allow government institutions, BI suppliers to gain a better understanding of BI adoption in Malaysian HEIs. By categorizing HEIs into separate categories, they can develop policies and customize the products best suited to their organizations, ultimately speeding up BI adoption among other HEIs. These relevant parties will be able to effectively monitor their policies and effectively allocate resources to areas of development that have been previously ignored and thereby allowing HEIs to adopt the most suitable technology for their institutions' needs.

Thirdly, relying only on the benefits of BI technology to ensure that they are adopted by organizations is not sufficient because other environmental, technological, individual and organizational considerations can contribute to the adoption of IT. Future BI literature studies are expected to guide the development of this research framework. This framework is likely to be a research tool for examining antecedents in the context of other HEI IT adoptions. The analysis of the slow rate of IT uptake in HEIs could be explored through further studies and ways to address barriers to BI adoption.

\section{Conclusion}

For more than two decades, BI has become an essential component of supporting organizational decision-making. BI adoption has reached a mature stage in large organizations, while HEIs are still slow to adopt BI. BI Organizational adoption is expected to help organizations achieve competitive advantages and enhance organizational performance by making operational data an advantage that drives strategic decisions. However, this study notes the lack of an embedded research framework to examine the antecedents and outcomes of BI adoption, particularly in the context of HEIs. 


\section{MInstitute ${ }_{\text {Mnk }}^{\text {Macrothin }}$}

International Journal of Social Science Research

ISSN 2327-5510

2021, Vol. 9, No. 2

The research methodology is expected to form the basis for the potential adoption of HEI IT advancements, specifically innovations related to decision support systems. These findings outline the main background and outcomes of HEI adoption in Malaysia.

On the basis of these results, government agencies, IT service providers and researchers should recognize these antecedent factors and give adequate attention and consideration to HEIs in Malaysia in order to increase the frequency of BI adoption. The researcher also expects the empiric findings from the validated template in this research to provide further knowledge of the benefits of HEI BI adoption in Malaysia. The researcher also hopes that the model of this study can be used to analyze other IT adoptions in the context of the HEIs.

\section{Acknowledgments}

This work was supported by the Universiti Sains Malaysia under Bridging Grant Scheme for the research (304/PPAMC/6316078).

\section{References}

Ali, A., Rahman, M. S. A., \& Ismail, W. N. S. W. (2012). Predicting continuance intention to use accounting information systems among SMEs in Terengganu, Malaysia. International Journal of Economics and Management, 6(2), 295-320.

Alshawi, S., Missi, F., \& Irani, Z. (2011). Organisational, technical and data quality factors in CRM adoption - SMEs perspective. Industrial Marketing Management, 40(3), 376-383. https://doi.org/10.1016/j.indmarman.2010.08.006

Behyan, M., Mohamad, O., \& Omar, A. (2015). Influence of internationalization orientation on export performance: In the perspective of Malaysian manufacturing firms. Journal of Business and Industrial Marketing, 83-95. https://doi.org/10.1108/JBIM-05-2012-0091

Boonsiritomachai, W., McGrath, G. M., \& Burgess, S. (2016). Exploring business intelligence and its depth of maturity in Thai SMEs. Cogent Business \& Management, 3(1), 1-17. https://doi.org/10.1080/23311975.2016.1220663

Cohen, J. (1988). Statistical power analysis for the behavioral sciences. In Statistical Power Analysis for the Behavioral Sciences (Vol. 2). https://doi.org/10.1234/12345678

Davis, J., Miller, G. J., \& Russell, A. (2006). Information revolution: Using the information evolution model to grow your business (Vol. 4). John Wiley \& Sons.

Dawson, S., Heathcote, L., \& Poole, G. (2010). Harnessing ICT potential: The adoption and analysis of ICT systems for enhancing the student learning experience. International Journal of Educational Management, 24(2), 116-128. https://doi.org/10.1108/09513541011020936

DELL. (2013). Academic Analytics Business Intelligence for Higher Education. Campus Technology.

Dresner Advisory Service. (2018). 2018 Wisdom of Crowd: Business Intelligence Market Study. 


\section{I Macrothink}

International Journal of Social Science Research

ISSN 2327-5510

2021, Vol. 9, No. 2

Duan, X., Deng, H., \& Corbitt, B. (2012). What Drives the Adoption of Electronic Markets in Australian Small-and- Medium Sized Enterprises? An Empirical Study. In Australasian Conference on Information Systems (23rd: 2012: Geelong, Victoria, pp. 1-11).

EDUCASE. (2017). Higher Education IT Trend 2017. Retrieved from https://library.educause.edu/ /media/files/library/2017/8/ers1712.pdf

Elbashir, M. Z., Collier, P. A., \& Davern, M. J. (2008). Measuring the effects of business intelligence systems: The relationship between business process and organizational performance. International Journal of Accounting Information Systems, 9(3), 135-153. https://doi.org/10.1016/j.accinf.2008.03.001

Falk, R., \& Miller, N. B. (1992). A Primer for Soft Modeling. Open Journal of Business and Management, 2(April), 103.

Gartner. (2013). BI software market to grow 9\% in Malaysia. Gartner Press Release. Retrieved from https://www.digitalnewsasia.com/tech-at-work/bi-software-market-to-grow-9pc-in-malaysia7 pc-globally-gartner

Ghobakhloo, M., Arias-Aranda, D., \& Benitez-Amado, J. (2011). Adoption of e - commerce applications in SMEs. Industrial Management \& Data Systems, 111(8), 1238-1269. https://doi.org/10.1108/02635571111170785

Grandon, E. E., \& Pearson, J. M. (2004). Electronic commerce adoption: An empirical study of small and medium US businesses. Information and Management, 42(1), 197-216. https://doi.org/10.1016/j.im.2003.12.010

Hair, J. F., Hult, G. T. M., Ringle, C. M., \& Sarstedt, M. (2017). A Primer on Partial Least Squares Structural Equation Modeling (PLS-SEM). Long Range Planning (Second). SAGE Publications Inc. https://doi.org/10.1016/j.lrp.2013.01.002

Hair Jr, J. F., Sarstedt, M., Hopkins, L., \& Kuppelwieser, V. G. (2014). Partial least squares structural equation modeling (PLS-SEM): An emerging tool in business research. European business review.

Hocevar, B., \& Jaklič, J. (2010). Assessing Benefits of Business Intelligence Systems-A Case Study. Management, 15, 87-119.

Iacovou, C. L., Benbasat, I., \& Dexter, A. S. (1995). Electronic data interchange and small organizations: Adoption and impact of technology. MIS Quarterly, 465-485. https://doi.org/10.2307/249629

IDC. (2018). Data Age 2025: The Digitization of the World from Edge to Core. International Data Corporation. Retrieved from https://www.seagate.com/files/www-content/our-story/trends/files/idc-seagate-dataage-white paper.pdf

Ifinedo, P. (2011). An empirical analysis of factors influencing Internet/E-business 
technology adoption by SMEs in Canada. International Journal of Information Technology \& Decision Making, 10(04), 731-766. https://doi.org/10.1142/S0219622011004543

JISC. (2016). Learning analytics in higher education: A review of UK and international practice. $\quad$ Retrieved $\quad$ December 2017 , from https://www.jisc.ac.uk/reports/learning-analytics-in-higher-education

Kaplan, R. S., \& Norton, D. P. (1996). The Balanced Scorecard: Translating Strategy in Action. Harvard Business School Press. Boston, MA. https://doi.org/10.1109/JPROC.1997.628729

Kendall, J. D., Tung, L. L., Chua, K. H., Ng, C. H. D., \& Tan, S. M. (2001). Receptivity of Singapore's SMEs to electronic commerce adoption. Journal of Strategic Information Systems, 10(3), 223-242. https://doi.org/10.1016/S0963-8687(01)00048-8

Lertwongsatien, C., \& Wongpinunwatana, N. (2003). E-commerce adoption in Thailand: An empirical study of small and medium enterprises (SMEs). Journal of Global Information Technology Management, 6(3), 67-83. https://doi.org/10.1080/1097198X.2003.10856356

Mad Lazim, H., \& Ramayah, T. (2010). Maintenance strategy in Malaysian manufacturing companies: a total productive maintenance (TPM) approach. Business Strategy Series, 11(6), 387-396. https://doi.org/10.1108/17515631011093098

Malaysian Ministry of Education. (2015). Malaysia Education Blueprint 2015-2025 (Higher Education). Malaysian Ministry of Education (Vol. 2025). https://doi.org/10.5923/j.ijis.20120206.05

Moore, G. C., \& Benbasat, I. (1991). Development of an instrument to measure the perceptions of adopting an information technology innovation. Information Systems Research, 2(3), 192-222. https://doi.org/10.1287/isre.2.3.192

Ong, V. K. (2016). Business Intelligence and Big Data Analytics for Higher Education: Cases from UK Higher Education Institutions. Information Engineering Express, 2(1), 65-75. https://doi.org/10.1109/IIAI-AAI.2015.178

Olszak, C. M. (2016). Toward Better Understanding and Use of Business Intelligence in Organizations. Information Systems Management, 33(2), 105-123. https://doi.org/10.1080/10580530.2016.1155946

Owusu, A., \& Moyaid, S. A. (2016). An Integrated Model for Determining Business Intelligence Systems Adoption and Post-Adoption Benefits in Banking Sector. Journal of Administrative and Business Studies, 2(2), 84-100. https://doi.org/10.20474/jabs-2.2.4

Popovič, A. L., Turk, T., \& Jaklič, J. (2010). Conceptual Model of Business Value of Business Intelligence Systems. Management: Journal of Contemporary Management, 15(1), 5-29. https://doi.org/http://www.efst.hr/management/

Puklavec, B., Oliveira, T., \& Popovič, A. L. (2018). Understanding the determinants of business intelligence system adoption stages: An empirical study of SMEs. Industrial 
Management \& Data Systems, 118(1), 236-261. https://doi.org/10.1108/IMDS-05-2017-0170

Qushem, U. (2017). The Trend of Business Intelligence Adoption and Maturity (pp. 532-537). 2nd International Conference on Computer Science and Engineering.

Rahmat, A., Ahmad, A., \& Ta'a, A. (2016). Business Intelligence Readiness for Higher Learning Institution (IHL): Preliminary Study and Research Model. British Journal of Applied Science \& Technology, 15(5), 1-10. https://doi.org/10.9734/BJAST/2016/24383

Ramamurthy, K., Sen, A., \& Sinha, A. P. (2008). An empirical investigation of the key determinants of data warehouse adoption. Decision Support Systems, 44(4), 817-841. https://doi.org/10.1016/j.dss.2007.10.006

Ramdani, B., Chevers, D., \& A. Williams, D. (2013). SMEs' Adoption of Enterprise Applications: A Technology-Organisation-Environment model. Journal of Small Business and Enterprise Development, 20(4), 735-753. https://doi.org/10.1108/JSBED-12-2011-0035

Ringle, C. M., \& Sarstedt, M. (2016). Gain more insight from your PLS-SEM results the importance-performance map analysis. Industrial Management and Data Systems. https://doi.org/10.1108/IMDS-10-2015-0449

Sarosa, S., \& Underwood, J. (2005). Factors Affecting IT Adoption within Indonesian SMEs: Manager's Perspectives (pp. 59-68). 9th Pacific Asia Conference on Information Systems PACIS. Retrieved from http://www.scopus.com/inward/record.url?eid=2-s2.0-80053483975\&partnerID=40\&md5=9f ef286aea7f9aac3abe0559a62884bf

Sekaran, U., \& Bougie, R. (2016). Research Methods for Business: A Skill Building Approach (7th ed.). John Wiley \& Sons Ltd.

Siew-Phaik, L., Downe, A. G., \& Sambasivan, M. (2013). Strategic alliances with suppliers and customers in a manufacturing supply chain: From a manufacturer's perspective. Asia-Pacific Journal of Business Administration. https://doi.org/10.1108/APJBA-11-2012-0077

Sujitparapitaya, S., Shirani, A., \& Roldan, M. (2012). Business Intelligence Adoption in Academic Administration: An Empirical Investigation. Issues in Information Systems, 3(2), 112-122. https://doi.org/10.1016/0378-7206(86)90027-3

Wong, B. T. M. (2017). Learning analytics in higher education: An analysis of case studies. Asian Association of Open Universities Journal, 12(1), 21-40. https://doi.org/10.1108/AAOUJ-01-2017-0009

Wong, B. T. M., Li, K. C., \& Choi, S. P. M. (2018). Trends in learning analytics practices: A review of higher education institutions. Interactive Technology and Smart Education, 15(2), 132-154. https://doi.org/10.1108/ITSE-12-2017-0065 


\section{Macrothink}

International Journal of Social Science Research

ISSN 2327-5510

\section{Copyrights}

Copyright for this article is retained by the author(s), with first publication rights granted to the journal.

This is an open-access article distributed under the terms and conditions of the Creative Commons Attribution license (http://creativecommons.org/licenses/by/4.0/). 